\title{
?12 tinbergen
}

TI 2020-055/VII

Tinbergen Institute Discussion Paper

\section{Left Behind Voters, Anti-Elitism and Popular Will}

Benoit Crutzen ${ }^{1}$

Dana Sisak ${ }^{1}$

Otto Swank ${ }^{1}$

${ }^{1}$ Erasmus School of Economics, Department of Economics 
Tinbergen Institute is the graduate school and research institute in economics of Erasmus University Rotterdam, the University of Amsterdam and Vrije Universiteit Amsterdam.

Contact: discussionpapers@tinbergen.nl

More TI discussion papers can be downloaded at https://www.tinbergen.nl

Tinbergen Institute has two locations:

Tinbergen Institute Amsterdam

Gustav Mahlerplein 117

1082 MS Amsterdam

The Netherlands

Tel.: +31(0)205984580

Tinbergen Institute Rotterdam

Burg. Oudlaan 50

3062 PA Rotterdam

The Netherlands

Tel.: +31(0)10408 8900 


\title{
Left Behind Voters, Anti-Elitism and Popular Will
}

\author{
Benoit S. Y. Crutzen, Dana Sisak and Otto H. Swank* \\ (Erasmus School of Economics / Tinbergen Institute)
}

September 2, 2020

\begin{abstract}
Two common characteristics of populism are anti-elitism and favoring popular will over expertise. The recent successes of populists are often attributed to the common people, the majority of voters, being left behind by mainstream parties. This paper shows that the two characteristics of populism are responses to the common people being left behind. We develop a model that highlights two forces behind electoral success: numbers and knowledge. Numbers give the common people an electoral advantage, knowledge the elite. We show that electoral competition may lead parties to cater to the elite's interest, creating a left-behind majority. Next, we identify conditions under which a left-behind majority encourages entry by a party offering an anti-elite platform. Finally, we identify conditions under which parties follow the opinion of the common people when that group would benefit from parties relying on experts.
\end{abstract}

Keywords: Electoral competition, Populism, Pandering, Information.

JEL Classification: D72, D83

*We thank Paul Bose, Josse Delfgaauw, Philipp Denter, Robert Dur, Aksel Erbahar, Aart Gerritsen, Jurjen Kamphorst, Sacha Kapoor, Hendrik Rommeswinkel as well as seminar, conference and workshop participants in Priorat 2018, Mannheim WWPE 2019, EPSA 2019, SAET 2019, Rotterdam 2019, MAPE Madrid 2019, Rotterdam 2020. 


\section{Introduction}

In the last decades, populism has been on the rise in several countries. Rodrik (2018) uses the label "populist" for a variety of politicians, ranging from Hugo Chavez in Venezuela to Donald Trump and Bernie Sanders in the U.S., to Marine le Pen in France. Though these politicians have different positions on a left-right wing scale, they have two traits in common. First, they claim to defend the interests of the common people against the elite (see also Acemoglu et al., 2013). Second, populist politicians often emphasize the wisdom of the common people. They tend to ignore expert advice, resulting in, for example, climate change skepticism or policies that disregard basic economic reasoning (Dornbush and Edwards, 1991). ${ }^{1}$ The following quote by Trump (2016) illustrates these two traits: ${ }^{2}$

"The only antidote to decades of ruinous rule by a small handful of elites is a bold infusion of popular will. On every major issue affecting this country, the people are right and the governing elites are wrong"

Voters have also grown increasingly disappointed with traditional politicians and parties in the last decades (Stiglitz 2002, Acemoglu et al. 2013, Algan et al. 2017, Rodrik 2018). An often invoked reason for this decline in contentment and trust is the perception among the electorate that traditional politicians do not cater enough to their interests, and prefer to put forward policies that benefit especially the elite, that is, the more educated, informed, and wealthy voters. Acemoglu (2020) sums up nicely this view ${ }^{3}$ :

"[...] Democrats (and all other interested parties) need to find a better way to communicate with the millions who voted for Trump because they felt - and, in many cases, truly were - left behind economically and ignored politically."

\footnotetext{
${ }^{1}$ In Latin America, this has led to overly expansionary policies.

${ }^{2}$ https://www.wsj.com/articles/let-me-ask-america-a-question-1460675882

${ }^{3}$ https://www.project-syndicate.org/commentary/trump-fascist-parallels-unhelpful-by-daronacemoglu-2020-01
} 
The main objective of this paper is twofold. The first objective is to explain the above observation that millions of citizens are ignored politically. To this end, we develop a simple model of electoral competition between two parties in a society consisting of two groups, the better informed (the elite) and the less informed (the common people). The key feature of the model is that the consequences of policies are uncertain. The consequences can benefit both groups, can hurt both groups, or can have distributional consequences, that is, be favorable to one group but unfavorable to the other. In our model better informed, that is belonging to the elite, means being more able to assess policy consequenes. The model reveals a fundamental bias towards the better informed. We identify a condition showing that electoral competition leads parties to cater to the elite's interest even though the elite forms the minority group. Our model thus uncovers one reason why so many voters have lost faith in established parties.

Our second objective is to explain the two characteristics of populist policies discussed above: anti-elitism and favoring popular will over expert opinion. To this end, we study two extensions of our model. First, we allow for entry of a third party after the two established parties have chosen their platforms. We show that if the policy is sufficiently likely to be distributional, a bias towards the elite of the established parties leads to entry of a third party with an anti-elite platform that receives the support of all the common people. Importantly, the anti-elite platform is not based on any investigation of the policy consequences for the common people. It is merely the opposite of what the established parties offer. By offering a platform that is not based on an investigation of the policy consequences for the common people, the entrant does not fully cater to their interest. We show that anti-elite platforms are not the result of ill-informed established parties. Anti-elite platforms derive their credibility from the information contained in elite-platforms.

In the second extension, parties can learn the consequences of the policy by investigating them, as in the basic model, or by conducting a poll among the common people. We identify the conditions under which parties pander to the desires of the common people, while the common people would benefit from parties investigating policy consequences through experts. In situations consistent with an elite bias in 
the basic model, the higher the probability is that the election revolves around a distributional policy, the more parties rely on the opinion of the common people instead of that of experts.

In our model, uncertainty about the policy consequences for the common people drives our results. Using survey data, Guiso et al. (2019) and Dal Bó et al. (2019) report that citizens who feel more insecure are more likely to vote for populist parties. In recent surveys of the literature on populism, Guriev and Papaioannou (2020) and Noury and Roland (2020) discuss globalization, automation, and the recession due to the financial crisis as drivers of populism. These three phenomena have all contributed to economic insecurity for large groups of voters. Panunzi et al. (2020) have taken economic insecurity as the starting point of a theoretical explanation for populism. They argue that insecurity, in combination with loss aversion, has increased the demand for risky policies. Their paper explains nicely the existence of coalitions of rich and disappointed citizens. However, it is less able to explain anti-elitism and populists' emphasis on popular will.

Our analysis shares with Panunzi et al. (2020) that insecurity is a driver of populism. However, in our model, insecurity is not due to exogenous shocks. It is due to the possibility that policy choices may come with adverse consequences for the common people. Our contribution focuses on uncertainty about the possibility that implemented policies reduce the welfare of the common people. We think of trade liberalization as a good example of a policy that fits our model. Politicians have portrayed globalization as progress that should be accepted. They paid less attention to the potential adverse consequences for workers in many industries. Once these distributional consequences became more visible opposition to globalization and to supranational institutions, one form of anti-elitism, increased (Stiglitz, 2002, Rodrik, 2018 and Guriev and Papaioannou, 2020). Policies against climate change are another example. Established parties portray such policies as a necessity for all. Yet, little attention is paid to their potential distributional consequences. In practice, the extent to which policy creates insecurity varies over time. In the decades after the Second World War, policies that led to the welfare state clearly fostered security for the common people. It is not surprising that those policies did 
not lead to anti-elitism.

\section{Literature}

There is a large empirical literature that tries to identify causes for the rise of populist parties. ${ }^{4}$ On the demand for populist policies, two strands in this literature can be distinguished. The first strand consists of studies that test the cultural backlash hypothesis, stating that large groups of citizens reject the cultural shift of the last five decades towards more post-materialist values. This cultural shift has been accompanied by a declining emphasis on redistribution, the left versus right conflict, and by more polarization about social values (Guiso et al. 2019). Inglehart and Norris (2017) use data from the European Social Survey to identify which individual characteristics are good predictors for voting for populist parties. They find that older generations and the less educated have less trust in national and international institutions, have stronger anti-immigrant attitudes, and vote more for populist parties. They view their results as supportive of the cultural backlash hypothesis. The second strand emphasizes economic inequality and economic insecurity as the main drivers of the rise of populism. For example, Guiso et al. (2019) find that support for populist parties is correlated with economic insecurity. Autor et al. (2016) and Colantone and Stanig (2018a, 2018b) report correlations between populist support and adverse trade shocks. Clearly, the cultural and economic approach to populism do not exclude each other. Trust in institutions and economic insecurity are likely to be mutually dependent and be affected by past, current, and expected policy (Algan et al., 2017, Dal Bó et al., 2019, Gennaioli and Tabellini, 2019, and Guiso et al. 2019).

Most empirical studies on populism are at most loosely based on economic theory. For example, Guiso et al. (2019) assume that citizens' disappointment with established parties is a positive function of how much insecurity they experience. This disappointment either induces citizens to abstain from voting or to vote for populist parties. Though plausible, an important puzzle remains. Why did estab-

\footnotetext{
${ }^{4}$ For excellent surveys, see Guriev and Papaioannou (2020) and Noury and Roland (2020).
} 
lished parties not protect citizens better against insecurity? Rodrik (2018) hints to a possible answer to this question by arguing that politicians (and their advisors) have long ignored the distributional consequences of globalization. Special interests were leading, not the common interest. We build on some of these arguments to offer a theory of populism driven by citizens' disapointment with the policies put forward by traditional parties.

Turning to other theoretical contributions on populism, Acemoglu et al. (2013) explain why the common people lost trust in established parties in countries with high levels of inequality and weak political institutions. In those countries, many politicians engage in corruption and political betrayal. They pay lip service to the needs of the common people, but actually serve the interests of an elite. This practice creates room for populist politicians to signal to voters that they do not cater to the interests of the elite. To this end, they choose platforms that are biased away from that preferred by the median voter. The theory of populism proposed by Acemoglu et al. (2013) offers several insights into populism in Latin America, where corruption is commonplace. It is less able to explain the rise in populism in EU countries. Moreover, the model of populism employed by Acemoglu et al. (2013) is less suitable to explain populists' emphasis on popular will.

Bernhardt et al. (2019) consider a repeated, electoral game between a farsighted, welfare maximizing politician and a short sighted, office-seeking candidate when voters also have a bias towards the short term. The key electoral issue at each election is the how to allocate resources between investment and consumption. They show how the presence of the office-seeking candidate pushes the farsighted politician to offer a per-period platform that is not the welfare-maximising one, promising to spend a too high share of resources on consumption. Our mechanism behind the suboptimality of the electoral equilibrium is very different, as we focus on the trade off between numbers and information to explain why politicians may sometimes propose policies that hurt the majority of the population.

Levy et al. (2020) and Morelli et al. (2020) develop theories that are centered around information, like us. ${ }^{5}$ Levy et al. (2020) differs from ours along two im-

\footnotetext{
${ }^{5}$ Agranov et al. (2020) studies a model in which the median voter loses faith in the announce-
} 
portant dimensions. First, they have a repeated game whereas we focus on a one shot game. Second and more importantly, whereas in our model all actors are fully rational, in their model politicians and citizens are heterogeneous in their views of the world. Specifically, one type holds the correct view. The other views the world through a simplistic, incorrect lense. Their model generates political cycles with either type of politician taking turns in office. This is because when the politician who holds the correct view of the world is in office, he implements the right policies but his support among voters with simplistic views gradually dies out, as these voters favour simple solutions to what are actually complex problems. Once in office, the politician with simplistic views also eventually generates his own electoral defeat through his continuous use of simplistic policies which become increasingly inappropriate for the policy problem at hand.

In Morelli et al. (2020), information is costly. This allows simple, fixed policies to be successful. In contrast, in our model information is either free or its cost is infinitesimal. Also, all policies have the same degree of complexity. Policies that do not benefit the majority can be part of equilibrium in our model because the minority is better informed and thus less divided as a group when voters follow their signals.

\section{The Basic Model}

The electorate is represented by a continuum of voters with mass 1 . There are two groups, the Elite and the Common people; $j \in\{E, C\}$. The size of group $E$ is $\sigma<\frac{1}{2}$, and that of group $C$ is $1-\sigma$.

The election revolves around policy $x \in\{0,1\}$. We denote by $x=1$ implementation, and by $x=0$ maintaining status quo. The contribution of the policy to the payoff of citizen $i$ of group $j$ equals:

$$
u_{i, j}=w_{j} x
$$

where $w_{j} \in\{-1,1\}$ is group $j$ 's state of the world. With probability $\alpha$, the two ments of the elite because of increased misalignment of preferences. 
group-specific states of the world coincide: $w_{E}=w_{C}$; with probability $1-\alpha$ they conflict: $w_{E} \neq w_{C}$. Finally, $w_{E}=1$ with probability $\frac{1}{2}$. Table 1 presents the probabilities of the states, and how the states affect the payoffs of citizens of the two groups.

\begin{tabular}{c||cc}
$w_{C} \backslash w_{E}$ & -1 & 1 \\
\hline \hline-1 & $\frac{1}{2} \alpha$ & $\frac{1}{2}(1-\alpha)$ \\
1 & $\frac{1}{2}(1-\alpha)$ & $\frac{1}{2} \alpha$
\end{tabular}

Table 1: Probabilities of the states

We interpret $\alpha$ as the probability with which the policy is about a public good. $1-\alpha$ is the probability that the policy is distributive. $\alpha$ is common knowledge and can thus be interpreted as a common prior belief about the type of policy the election is likely about. In practice, it is often the case that the consequences of policies are more uncertain for some groups than for other groups. We deliberately choose a neutral setting in which the consequences of the policy are equally uncertain for both groups. As a result, any possible bias in parties' platforms choices towards one of the states is not the result of different probabilities of the two states. At the end of Section 4, we discuss the consequences of switching to non-neutral settings for our main result.

At the beginning of the game, each member $i$ of group $j$ receives a signal about state $w_{j}, s_{i, j} \in\{-1,1\}$. Citizen $i$ 's signal reveals the state of the world with probability $p_{j}=\operatorname{Pr}\left(w_{j}=s_{i, j} \mid s_{i, j}\right) \geq 1 / 2$. With probability $\left(1-p_{j}\right)$, $i$ 's signal conflicts with the state of the world. We assume that $p_{E}>p_{C}$, capturing the idea that members of group $C$ are less able to assess whether implementation of the policy is in their interests than members of group $E$. One reason might be that members of group $C$ are less educated than members of group $E$. An alternative reason is that members of group $C$ are relatively alienated from politics.

There are two parties, $p \in\{1,2\}$. Each party $p$ receives a signal about $w_{E}$, $s_{p, E} \in\{-1,1\}$, and a signal about $w_{C}, s_{p, C} \in\{-1,1\}$. Each signal of party $j$ is correct with probability $q \geq p_{E}$. Party signals are conditionally independent. 
After having received their signals, parties simultaneously choose platforms. Party $p$ 's platform, $x_{p} \in\{0,1\}$, shows its decision about $x$, if elected. The main purpose of the basic model is to show that in a two-party system, electoral competition leads to a bias in party platforms towards the elite' interests. We identify a condition under which the unique equilibrium of the basic model is one in which both parties set platforms in line with $w_{E}$ and thus ignore $w_{C}$. Our result that parties consistently ignore $s_{p, C}$ is most forceful when signals are for free. For this reason, we assume in the basic setting that signals are for free.

Parties receive utility from holding office. Party $p$ 's payoff is $u_{p}=1$ if it wins the election, and $u_{p}=0$ if it is defeated.

At the election, citizens vote simultaneously. Each citizen either votes for party 1 or for party 2. There is no abstention. We denote by $v_{i, j} \in\left\{v^{1}, v^{2}\right\}$, the vote decision of member $i$ of group $j$, where $v^{p}$ is a vote for party $p$. When voting, each citizen knows her own signal, the common prior $\alpha$, observes parties' platforms and forms beliefs about which signal(s) each party used to set its platform and how each party used such signal(s), namely let its platform match or conflict with the signal(s).

To solve the model, we identify Perfect Bayesian Equilibria (PBE), in which parties follow pure strategies and citizens follow symmetric vote strategies. By symmetric vote strategies, we mean that members of the same group follow identical vote strategies. Party $p$ 's strategy consists of a platform decision, $x_{p}$, conditional on $s_{p, E}$ and $s_{p, C}$. On the basis of her signal, $s_{i, j}$, and parties' platforms, $x_{1}$ and $x_{2}$, each citizen $i$ of group $j$ decides whether to vote for party $1, v_{i, j}=v^{1}$ or for party 2 , $v_{i, j}=v^{2}$. The voting strategy of citizen $i$ of group $j$ is denoted by $\nu_{i, j}\left(x_{1}, x_{2}, s_{i, j}\right)$, giving the probability with which citizen $i$ of group $j$ chooses $v_{i, j}=v^{1}$, conditional on parties' platforms and her signal. We assume that if a voter is indifferent between $v^{1}$ and $v^{2}$, she chooses $v^{1}$ with probability $\frac{1}{2}{ }^{6}$ When voting, each citizen $i$ of group

\footnotetext{
${ }^{6}$ This assumption rules out equilibria where, e.g. party 1 always proposes $x_{1}=1$ and party 2 proposes $x_{2}=0$ and voters punish deviant parties by never voting for them. Such equilibria de facto reduce the election game to a referendum - parties play no active role in information aggregation. While we believe studying the advantages and disadvantages of referenda relative to
} 
$j$ has formed a belief about the probability that $w_{j}=1$. We denote the equilibrium belief of citizen $i$ of group $j$ about the probability that $w_{j}=1$, conditional on parties' equilibrium strategies and platforms, $\mathbf{x}=\left(x_{1}^{*}\left(s_{1, E}, s_{1, C}\right), x_{2}^{*}\left(s_{2, E}, s_{2, C}\right)\right)$, and her own signal by $\pi_{i, j}\left(x_{1}, x_{2}, s_{i, j} \mid \mathbf{x}\right)$.

In equilibrium:

1. Given equilibrium voters' strategies, $\nu_{i, j}^{*}\left(x_{1}, x_{2}, s_{i, j}\right)$, given equilibrium beliefs, $\pi_{i, j}\left(x_{1}, x_{2}, s_{i, j} \mid \mathbf{x}\right)$, and given $x_{1}^{*}\left(s_{1, E}, s_{1, C}\right), x_{2}$ is a best reply, conditional on $s_{2, E}$ and $s_{2, C}$. An analogous requirement holds for $x_{1}$.

2. Given equilibrium strategies of parties, $\mathbf{x}, \nu_{i, j}\left(x_{1}, x_{2}, s_{i, j}\right)=1$ (0) if $x_{1}$ yields a higher (lower) expected payoff to voter $i$ of group $j$ than $x_{2} . \nu_{i, j}\left(x_{1}, x_{2}, s_{i, j}\right)=$ $\frac{1}{2}$ if $x_{1}=x_{2}$.

3. All equilibrium beliefs about probabilities, $\pi_{i, j}\left(x_{1}, x_{2}, s_{i, j} \mid \mathbf{x}\right)$, result from Bayes' rule.

\section{Analysis}

\subsection{Voting decisions and belief formation}

We first consider the voting decision of a citizen given her beliefs $\pi_{i, j}\left(x_{1}, x_{2}, s_{i, j} \mid \mathbf{x}\right)$. Next, we discuss how these beliefs are formed. In Section 4.2, we derive parties' platform choices.

In the last stage of the game, each citizen votes for the party whose platform she believes maximizes her expected utility. If parties offer the same platforms, $x_{1}=x_{2}$, then beliefs are irrelevant and, by assumption, voters base their vote on a fair coin toss, $\nu_{i, j}^{*}\left(s_{i, j}, x_{2}, x_{2}\right)=\frac{1}{2}$. If parties offer different platforms, the vote decision of citizen $i$ of group $j$ is determined by her belief about the probability that $w_{j}=1$. If the voter believes that $w_{j}=1$ is more likely than $w_{j}=-1$, which implies that $2 \pi_{i, j}\left(x_{1}, x_{2}, s_{i, j} \mid \mathbf{k}, \mathbf{x}\right)-1>0$, she votes for the party offering $x_{p}=1$, which is party electoral competition is an interesting question, we do not address it in the current paper. 
1 if $x_{1}-x_{2}>0$ and party 2 if $x_{1}-x_{2}<0$. Thus, the strategy of citizen $i$ of group $j$ satisfies, for all $\left(x_{1}, x_{2}, s_{i, j}\right)$ :

$$
\nu_{i, j}^{*}\left(s_{i, j}, x_{1}, x_{2}\right)=\left\{\begin{array}{cl}
1 & \text { if }\left(2 \pi_{i, j}\left(x_{1}, x_{2}, s_{i, j} \mid \mathbf{x}\right)-1\right)\left(x_{1}-x_{2}\right)>0 \\
\frac{1}{2} & \text { if }\left(2 \pi_{i, j}\left(x_{1}, x_{2}, s_{i, j} \mid \mathbf{x}\right)-1\right)\left(x_{1}-x_{2}\right)=0 \\
0 & \text { if }\left(2 \pi_{i, j}\left(x_{1}, x_{2}, s_{i, j} \mid \mathbf{x}\right)-1\right)\left(x_{1}-x_{2}\right)<0 .
\end{array}\right.
$$

Since beliefs are irrelevant if $x_{1}=x_{2}$, we focus on belief formation if $x_{1} \neq x_{2}$. In order to characterize aggregate voting behavior in group $j$, we only need to know whether the sign of $2 \pi_{i, j}\left(x_{1}, x_{2}, s_{i, j} \mid \mathbf{x}\right)-1$ depends on the realization $s_{i, j}$. Suppose this is the case. Then, if $x_{1} \neq x_{2}$, votes of members of group $j$ are divided over both platforms as members follow the realization of their signals. If the sign of $2 \pi_{i, j}\left(x_{1}, x_{2}, s_{i, j} \mid \mathbf{x}\right)-1$ does not depend on the realization of $s_{i, j}$, group $j$ votes with a united front. In the latter case the evidence about $w_{j}$ provided through the platform choices of the parties is so strong that the private signal $s_{i, j}$ is dominated. The following Lemma identifies which scenarios lead group $j$ to vote with a united front in situations in which each party $p$ chooses its platform to match either $s_{p, E}$ or $s_{p, C} \cdot{ }^{7}$

Lemma 1 Consider equilibria where each party $p$ bases its platform on either $s_{p, E}$ or $s_{p, C}$. Citizens of group $j$ vote with a united front iff one party based its platform on $s_{p, E}$ and the other party based its platform on $s_{p, C}$, and $\alpha<\widehat{\alpha}\left(p_{j}\right)$ with $\widehat{\alpha}\left(p_{j}\right)=$ $\frac{\left(2 p_{j}-1\right) q^{2}-(2 q-1) p_{j}}{(2 q-1)\left(p_{j}+q-2 p_{j} q\right)}>\frac{1}{2}$.

The proof of this lemma and all other claims that are not proven in the main text can be found in the Appendix.

Lemma 1 presents the conditions under which voters cast their ballot for a platform consistent with their private signals when parties base their platforms on a signal about one of the states of the world. If parties offer different platforms,

\footnotetext{
${ }^{7}$ We say that a party $p$ matches a signal $s_{p, j}$ or bases its platform on a signal $s_{p, j}$ if that party proposes $x_{p}=1$ whenever $s_{p, j}=1$ and $x_{p}=0$ whenever $s_{p, j}=-1$. We show in the proof of Proposition 1 that a party finds it always optimal to base its platform on a signal and to match that signal.
} 
$x_{1} \neq x_{2}$, and base them on their signals about the same state, citizens that anticipate parties' strategies infer that one party received a correct signal and one party received an incorrect signal. As a result, platforms do not contain information about the states, and it is optimal for citizens to vote in line with their private signals. If one party caters to the interests of the elite and the other party caters to the interests of the common people, platforms generally do contain information about the states. Yet, the higher is $\alpha$, the lower are voters' beliefs about the probability that parties received correct signals if $x_{1} \neq x_{2}$. Thus, if $\alpha>\hat{\alpha}\left(p_{j}\right)>\frac{1}{2}$ and $x_{1} \neq x_{2}$, each voter follows her signal even though one of the parties caters to her interests.

Note that the threshold $\widehat{\alpha}\left(p_{j}\right)$ in Lemma 1 depends on the precision of group members' signals. As $p_{C}<p_{E}$, it is more likely for group $C$ voters than for group $E$ voters that their private signal is dominated by the information contained in the platform choices. Thus, all else equal, group $C$ voters are more likely to vote with a united front.

\subsection{Platforms}

Now we turn to the platform choices of parties. We say that party $p$ caters to the interest of group $j$ if it bases $x_{p}$ on $s_{p j}$. Note that whether party $p$ caters to the interests of group $E$ or group $C$ is only relevant if $s_{p, C} \neq s_{p, E}$. If $s_{p, C}=s_{p, E}$, the party also serves the interests of the other group, but unintentionally. Proposition 1 presents the unique equilibrium of the basic model.

Proposition 1 Consider the basic model. In the unique equilibrium of the game, both parties cater to the interests of the elite if $\sigma p_{E}+(1-\sigma)\left(1-p_{C}\right)>\frac{1}{2}$, and cater to the interests of the common people if $\sigma p_{E}+(1-\sigma)\left(1-p_{C}\right)<\frac{1}{2}$. Voters follow their private signals if $x_{1} \neq x_{2}$. They toss a fair coin if $x_{1}=x_{2}$.

Proposition 1 identifies a bias of electoral competition towards more knowledgeable voters. Even though group $C$ constitutes the majority, both parties cater to the elite minority if $\sigma p_{E}+(1-\sigma)\left(1-p_{C}\right)>\frac{1}{2}$ holds. Only if a) the majority is large enough, or b) the difference in knowledgeability, $p_{E}-p_{C}$, is not too large, this bias towards the elite is overcome. Figure 1 illustrates Proposition 1. 


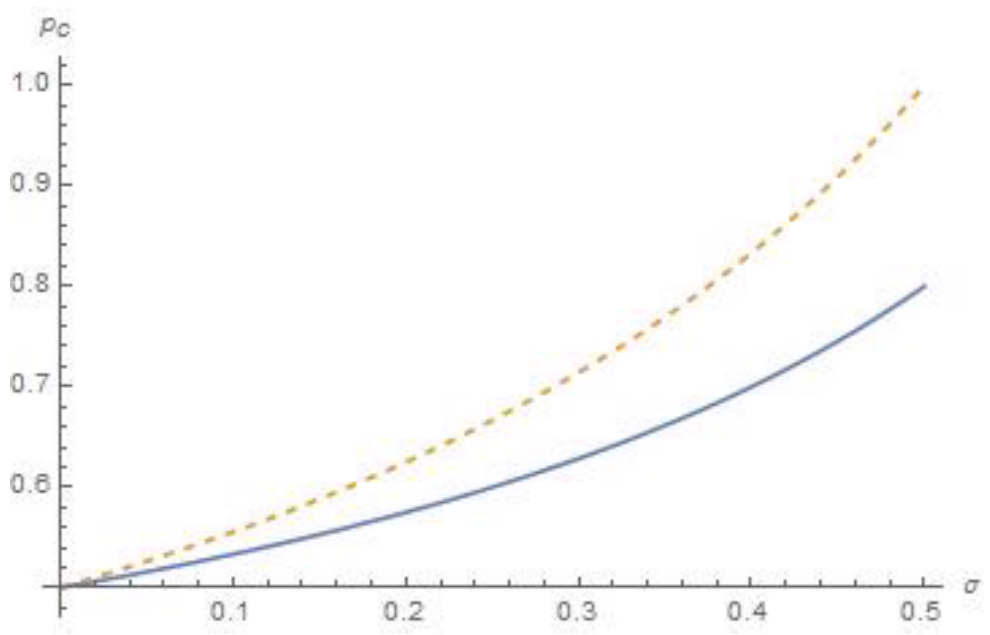

Figure 1: Maximum values of $p_{C}$ for which $\sigma p_{E}+(1-\sigma)\left(1-p_{c}\right)>\frac{1}{2}$. The blue solid curve holds for $p_{E}=0.8$. The orange dashed curve holds for $p_{E}=1$.

Proposition 1 highlights that two characteristics of the society our model describes drive parties' platform strategies: the sizes of the two groups, numbers, and how well informed members of the two groups are, knowledge. While the common people outnumber the elite in case they show a united front, i.e. when they all vote for the same party, this is not true in case the evidence on the groups' state is weak and the common people base their votes on their private signals. Because the signal of a group $C$ voter is noisier, the group is relatively more divided in their beliefs about the optimal policy and subsequent voting decisions. $\sigma p_{E}+(1-\sigma)\left(1-p_{C}\right)=\frac{1}{2}$ delineates exactly the case where the informational disadvantage of group $C$ voters is compensated by their higher number. If $\sigma p_{E}+(1-\sigma)\left(1-p_{C}\right)>\frac{1}{2}$ holds, the election outcome is in the interests of group E,except when both parties' signals are wrong. Thus the electoral bias against group $C$ goes beyond the elite being better able to choose what is in their interest. Parties reinforce the bias.

The extent to which group $C$ voters suffer from the bias against them depends on $\alpha$. The lower is $\alpha$, the more they suffer in expected terms. This is consistent with research that finds that a) more educated citizens systematically indicate higher trust levels in political institutions than less educated ones (Inglehart and Norris, 2017) and b) individual trust also decreases with individual economic conditions, i.e. in times of low $\alpha$ (see e.g. Foster and Frieden, 2017 for the European Union). 
Also some studies have tried to measure such an elite bias directly. Gilens and Page (2014) use survey data on the opinions of individuals from different income brackets on 1779 policy proposals between 1981 and 2002 in the United States to proxy for their preferences. They find that implementation patterns for these proposals are most consistent with an (economic) elite bias. The preferences of the 90th income percentile are most predictive for the chance of implementation, while median preferences have no additional explanatory power. They also find that for many issues the interests of the elite and the median citizen are aligned (which points towards a situation with high $\alpha$ in our model $)^{8}$. The following corollary summarizes these insights from our model.

Corollary 1 For $\sigma p_{E}+(1-\sigma)\left(1-p_{C}\right)>\frac{1}{2}$ electoral competition leads to a "leftbehind" majority whose interests are only represented if they are aligned with the elite minority.

In the basic model, parties receive signals about the states for free. We have shown that if $\sigma p_{E}+(1-\sigma)\left(1-p_{C}\right)>\frac{1}{2}$, parties do no utilize their information about $w_{C}$. Clearly, if signals about $w_{C}$ were costly, parties would not acquire them. Parties would be ignorant about the needs of the common people. This prediction is consistent with recent empirical literature. Broockman and Skovron (2018) document for the US that state legislative politicians systematically misperceive citizens' opinions. Kalla and Porter (2020) run a field experiment designed to increase the knowledge of US state legislators on their constituents' policy preferences. A share of legislators was offered information from the 2016 Cooperative Congressional Election Study about their constituents' preferences. The vast majority of legislators failed to even access this information. This is in line with our finding that electoral competition does not (always) provide incentives to learn the needs of the common people.

To demonstrate the bias of electoral competition most clearly, we have assumed a neutral environment, in which ex ante the consequences of the reform are equally

\footnotetext{
${ }^{8}$ Schakel and van der Pas (2020) conduct a similar analysis for the Netherlands, focusing on differences in educational level. They find that the preferences of the highly educated best predict policy implementation.
} 
uncertain for the elite and the common people. In practice, however, the degree of uncertainty of a policy is rarely the same for the common people and the elite. Take the welfare programs implemented in many OECD countries in the second half of the previous century. Ex ante, the common people expected to benefit from these programs. It was less clear how the elite would fare under these programs. In our model this could be captured by assuming $\operatorname{Pr}\left(w_{C}=1\right)$ close to one and $\operatorname{Pr}\left(w_{E}=1\right)$ close to $\frac{1}{2}$. In such a world, no electoral bias against the common people arises. All members of group $C$ would vote for implementation.

The consequences of other policies are less uncertain for the elite and more uncertain for the common people. Stiglitz (2002) and Rodrik (2018) argued that in the last decades especially the elite expected to benefit from all kinds of trade and international agreements, but that the consequences of these agreements were more uncertain for the common people. In terms of our model, this means $\operatorname{Pr}\left(w_{C}=1\right)$ to be close to $\frac{1}{2}$ and $\operatorname{Pr}\left(w_{E}=1\right)$ to be close to 1 . In this environment, the electoral bias against the common people is even stronger than in the neutral case. The reason is that if uncertainty of a policy exclusively falls on group $C$, members of group $E$ vote in block for the platform that favors them. As a result, to obtain a majority, group $E$ needs relatively few "wrong" votes of members of group $C$. Figure 1 illustrates this case. The orange dashed curve gives the maximum values of $p_{C}$ for which the bias against the common people exists as a function of $\sigma$ when the elite does not face any uncertainty about the effects of the policy on their group, $\operatorname{Pr}\left(w_{E}=1\right)=1$.

\section{Populist Policies}

In the previous section, we described how in a two-party system electoral concerns lead to a focus on the more knowledgeable minority whenever the difference in knowledgeability between the elite and the common people is large enough. This creates a void on the political spectrum and, in turn, a demand for policies that are more in the interest of the common people. In this section, we study extensions of the baseline model that illustrate how this demand may lead to a supply of "populist" policies. 
In Subsection 5.1, we show that the inability of parties to serve the interests of the common people creates scope for the entry of a party that proposes an anti-elite platform. We define an anti-elite platform as a platform that (1) is not based on a signal received by the party that proposes the platform, and (2) is opposite to the platforms proposed by parties that do base platforms on signals they received. The latter part of our definition indicates that an anti-elite platform is a response to other platforms. This means that to model anti-elite platforms, we have to allow for the possibility that parties respond to each other's platform choices. ${ }^{9}$ To make our point about the emergence of an anti-elite platform most forcefully, we assume in the extended model that (1) parties have to incur an infinitesimal cost to observe the signals about the states, and (2) voters prefer informed parties all else equal. Even under these assumptions, an anti-elite platform offered by an uninformed entrant may exist in equilibrium. Moreover, if an entrant offers an anti-elite platform, it wins the election.

In Subsection 5.2, we study whether anti-elitism can be sustained also in the "long-run", not just as an entry strategy of a new party. We show that in a threeparty system, an equilibrium exists in which anti-elite platforms may arise, suggesting that anti-elitism can be a long-run phenomenon. In addition, equilibria exist in which either all parties cater to the interests of the common people or to the interests of the elite. Finally, in Subsection 5.3 we consider a second feature of populist policies, the claim that policies are based on the will of the common people typically paired with suspicion towards or even negation of expert opinion. We contrast the choice between platforms based on expert opinion and platforms based on polls among the common people.

\footnotetext{
${ }^{9}$ Our definition of anti-elitism is in line with empirical evidence on populist parties in, for example, the Netherlands: Louwerse and Otjes (2019) analyze opposition behavior of populist vs. non-populist parties in the Netherlands and find that populists are significantly less likely to use policy making and more likely to use scrutiny. It is also in line with empirical evidence on campaign communication styles. Nai (2018) finds that populists are significantly more likely to go negative and thus attack their opponent rather than advertise themselves than non-populist parties.
} 


\subsection{Entry and Anti-Elite Platforms}

We extend the basic model to allow for entry of a third party after party 1 and 2 have proposed their platforms. Specifically,

- Let there be two stages before the election. Party 1 and 2 simultaneously choose a platform in stage $1, x_{1}$ and $x_{2}$, respectively. Party 3 may enter in stage 2. If it enters, it chooses $x_{3} \in\{0,1\}$. Party 3 can condition its platform decision on $x_{1}$ and $x_{2}$ or on its signal regarding group $E$ or $C$. It only enters when it has a non-zero chance of being elected.

- At a cost $c$, each party $p$ receives private signals about $w_{E}$ and $w_{C}, I_{P} \in\{0,1\}$, where $I_{P}=0$ means that $p$ does not acquire information, and $I_{P}=1$ means that it does. We assume the cost of information $c$ to be infinitesimal. A party's information acquisition decision is not observed by other agents.

- Each voter casts her ballot for the party whose platform yields the highest expected utility. Denote by $\iota_{P}$ voters' beliefs about the probability that party $p$ acquired information, $I_{p}=1$. In case $x_{i}=x_{j}$ and $\iota_{i}>\iota_{j}$, voters do not cast their ballots for party $j$. This means that voters prefer parties that are informed. If the platforms of two or three parties are equal and (believed to be) based on the same information (even though they may be announced at different stages of the game), each voter randomizes her vote between those parties.

- When none of the parties receive a majority of votes, the parties that propose the same platform form a coalition. The rents to office, in total normalized to one, are divided among the coalition parties. ${ }^{10}$

We solve the model by identifying PBE. In addition to the requirements for a PBE of the basic model, we require $x_{3}$ to be an optimal response to $x_{1}$ and $x_{2}$, given voters' strategies and given beliefs.

\footnotetext{
${ }^{10}$ This assumption ensures that the more popular policy is chosen and thus coordination problems by voters in the presence of multiple parties offering the same platform are avoided.
} 
The next proposition characterizes the equilibrium strategies ${ }^{11}$ of the extended model.

Proposition 2 Consider the extended model with the possibility of entry. A unique equilibrium exists, in which party 1 and 2 acquire information, $I_{1}=I_{2}=1$, while party 3 never acquires information, $I_{3}=0$. Furthermore:

(1) If $\sigma p_{E}+(1-\sigma)\left(1-p_{C}\right)<\frac{1}{2}$, party 1 and 2 cater to the interests of the common people, and party 3 never enters;

(2) If $\sigma p_{E}+(1-\sigma)\left(1-p_{C}\right)>\frac{1}{2}$ and $\alpha<\alpha^{\prime} \equiv \frac{q^{2}-p_{C}[1-2 q(1-q)]}{2 q-1}<\frac{1}{2}$, party 1 and 2 cater to the interests of the elite, and, whenever $x_{1}=x_{2}$, party 3 enters with an anti-elite platform $x_{3} \neq x_{1}=x_{2}$ and stays out else;

(3) If $\sigma p_{E}+(1-\sigma)\left(1-p_{C}\right)>\frac{1}{2}$ and $\alpha>\alpha^{\prime}$, party 1 and 2 cater to the interests of the elite, and party 3 never enters;

(4) If party 3 did not enter, voters follow their private signals if $x_{1} \neq x_{2}$, and toss a coin if $x_{1}=x_{2}$. If party 3 entered following $x_{1}=x_{2}$, the common people all vote for party 3 and members of the elite toss a fair coin for party 1 and 2;

Proposition 2 presents several results. Item (1) shows that in an environment where party 1 and 2 acquire information and cater to the interests of the common people, entry by a third party is never profitable. The reason is that if party 1 and 2 cater to the interests of the common people and $\sigma\left(1-p_{E}\right)+(1-\sigma) p_{C}>\frac{1}{2}$, party 3 has no chance of getting into office. If $x_{3} \neq x_{1}=x_{2}$, members of group $C$ exclusively vote for party 1 and 2, irrespective of whether $x_{3}$ has been based on $s_{3, C}$. This means that if $x_{1}=x_{2}$, the only way for party 3 to gain office is to copy the platform of the other parties. But this means that party 3 has no incentive to acquire information. Citizens anticipate this, which implies $\iota_{3}=0$, and vote for party 1 or 2 for whom $\iota_{1}=\iota_{2}=1$. If $x_{1} \neq x_{2}$, not acquiring a signal dominates acquiring a signal for party 3 as well. To see this, suppose that party bases $x_{3}$ on $s_{3, C}$. If believed by members of group $C$, party 3 gains (joint) office with certainty. However, anticipating that any platform leads to office, party 3 has no incentive to

\footnotetext{
${ }^{11}$ To be concise, we omit the characterization of voter beliefs. They follow from applying Bayes' rule taking into account the equilibrium strategies of the parties.
} 
acquire information and thus again $\iota_{3}=0$. Hence, if party 1 and 2 cater to the interests of the common people, party 3 does not enter.

We regard Item (2) of Proposition 2 as the main result of this subsection. It shows that if in a two-party system the elite has electoral power and the policy is likely to be distributional, an equilibrium exists in which party 1 and 2 acquire information and cater to the interests of the elite, while party 3 does not acquire information and enters with an anti-elite platform in case $x_{1}=x_{2}$. At first glance, it may seem hard to understand why a citizen could benefit from a platform that is solely based on being against traditional parties' platforms and is not based on any signal. In equilibrium though, the "populist" platform is based on information - the signals of the traditional parties. If the policy is likely to be distributional this can even be more informative than one expert opinion on the interests of group $C . \alpha^{\prime}$ is the highest value of $\alpha$ for which $x_{1}=x_{2}$ contains sufficiently convincing information about $w_{C}$ to let the common people believe that $x_{3} \neq x_{1}=x_{2}$ is in their interests.

If $x_{1}=x_{2}$, why does party 3 not enter with a platform based on a signal about $w_{C}$ ? The reason is that acquiring information is dominated by not acquiring information and setting $x_{3} \neq x_{1}=x_{2}$ instead. Once the common people believe $x_{3}$ is based on $s_{3, C}$, they vote for party 3 when $x_{3} \neq x_{1}=x_{2}$, but party 3 has to share votes with the other parties when $x_{3}=x_{1}=x_{2}$. Thus party 3 has no incentive to actually acquire a signal about $w_{C}$ nor would it use such information if it were free. $^{12}$

Finally, why does party 1, for example, not deviate and cater to the common people instead? Such a deviation would not be observable to voters and thus they would still follow their signal when the platforms of party 1 and 2 differ and vote for party 3 when they are the same. Consequently, such a deviation only reduces the

\footnotetext{
${ }^{12}$ Di Tella and Rotemberg (2018) offer an explanation for the observation that voters sometimes seem to prefer incompetent politicians. In their model, voters are disappointment averse and more competent politicians are more likely to betray them. Our result offers an alternative explanation of why voters sometimes seem to prefer incompetent leaders. Interpreting competence as basing a platform on a signal, we identify situations where a platform based on the signal of the common people is not credible and thus this group prefers an uninformed leader over an informed leader that caters to the elite.
} 
chance of being elected as the elite holds electoral power when voters follow their signals.

One can verify that $\alpha^{\prime}$ is increasing in $q$ and decreasing in $p_{C}$. Hence, antielite platforms are not the result of ill-informed parties. They are a response to well-informed parties catering to the interest of the elite. Better informed common people, on the other hand, narrow the scope for anti-elite platforms.

Item (3) shows that when party 1 and 2 cater to the interests of the elite, there is not always scope for an anti-elite platform. As discussed above, $\alpha$ should be sufficiently small for the emergence of an anti-elite platform. Clearly, if $\alpha>\frac{1}{2}$, the common people are better off when party 1 and 2 cater to the interests of the elite than when party 1 and 2 do not use information about states at all. In expected terms, the interests of the common people and the elite are aligned. If,

by contrast, $\alpha^{\prime}<\alpha<\frac{1}{2}$, members of group $C$ suffer, in expectation, from the electoral bias towards the elite. Still, the anti-elite platform, $x_{3} \neq x_{1}=x_{2}$ will not receive unanimous support from group $C$ voters. The reason is that $\alpha$ close to 0.5 implies that the platforms of party 1 and 2 based on the elite signals are not very informative about the interests of the common people. They thus optimally respond by following their private signals and are thus divided in their vote. Interestingly, this implies that there exists a range of parameters where group $C$ voters are worse off when they become better informed, i.e. $p_{C}$ increases, as this may bring them from a situation with anti-elite entry to a situation without.

\subsection{Anti-Elitism in a Three-Party System}

The previous section illustrates the possibility of "populist" entry in response to the elite bias. We did not allow the traditional parties to delay their platform choice in anticipation of the entry of a third party. It represents a situation where a newcomer arrives as a second-mover later in the electoral competition and thus depicts populism in the "short run". Yet, once this newcomer has become an established party, traditional parties may pre-empt an anti-elite platform by proposing a platform themselves only in the second stage, making it impossible for the "populist" 
to condition its platform on the platforms of the traditional parties. In this section, we identify equilibria of our game in a symmetric two-stage, three-party system and show that anti-elite policies can be a "long-run" equilibrium phenomenon. We amend the model of the previous subsection as follows.

- We assume three symmetric parties $p \in\{1,2,3\}$.

- Each party $p$ can choose either to propose a platform in stage $1, t_{p}=1$, or to propose a platform in stage $2, t_{p}=2$. Proposed platforms are final. In stage 2, parties observe platforms proposed in stage 1. $x_{p, t_{p}}$ denotes the platform of party $p$ proposed in stage $t_{p}$.

The next proposition characterizes the equilibrium strategies of three Perfect Bayesian Equilibria of the amended game. ${ }^{13}$ If two parties propose platforms in period 1, and one party reacts on these platforms in period 2, we assume that party 3 reacts. Of course, analogous equilibria exists in which either party 1 or 2 reacts.

Proposition 3 Consider the two-stage, three-party model.

(1) There always exists a PBE, in which

- all parties acquire information, cater to the interests of the common people, and propose platforms simultaneously in the first stage, and

- if $x_{1,1}=x_{2,1}=x_{3,1}$, all parties gain office, while if $x_{i, 1}=x_{j, 1} \neq x_{z, 1}$ party $i$ and $j$ gain office.

(2) Suppose that $\sigma p_{E}+(1-\sigma)\left(1-p_{C}\right)>\frac{1}{2}$ and $\frac{q-p_{C}}{2 q-1} \equiv \alpha^{\prime \prime}<\alpha<\alpha^{\prime} \equiv \frac{q^{2}-p_{C}[1-2 q(1-q)]}{2 q-1} \leq$ $\frac{1}{2}$. Then, a PBE exists, in which

- party 1 and 2 acquire information and propose platforms in stage 1 that are based on $s_{1, E}$ and $s_{2, E}$, respectively, while party 3 never acquires information

\footnotetext{
${ }^{13}$ Apart from these equilibria, five other equilibria exist. In two of them, one party does not acquire information and the other two parties do. Essentially, these equilibria are similar to the equilibria discussed in Proposition 1. In the third equilibrium, all parties investigate $w_{E}$, and invert their signals. Parties that offer the same platforms receive votes from group $C$. This equilibrium exists for low values of $\alpha$. The last two are similar to item 1 and 3 in Proposition 3. However, rather than proposing platforms in stage 1, parties propose platforms in stage 2. These two equilibria require specific out-of-equilibrium beliefs.
} 
- if $x_{1,1} \neq x_{2,1}$, party 3 sets its platform in stage 2 randomly, and voters follow their private signals either voting for party 1 or 2 , and

- if $x_{1,1}=x_{2,1}$, party 3 proposes an anti-elite platform in stage $2, x_{3,2} \neq x_{1,1}=x_{2,1}$, which receives a majority of votes.

(3) Suppose that $\sigma+(1-\sigma)\left(1-p_{C}\right)>\frac{1}{2}$ and $\frac{q^{2}-p_{C}[1-2 q(1-q)]}{2 q-1} \equiv \alpha^{\prime}<\alpha<\frac{q+p_{C}-1}{2 q-1}$, or $\alpha \geq \frac{q+p_{C}-1}{2 q-1}$. Then, a PBE exists in which

- all parties acquire information, cater to the interests of the elite, and propose platforms simultaneously in the first stage, and

- if $x_{1,1}=x_{2,1}=x_{3,1}$, all parties gain office, while if $x_{i, 1}=x_{j, 1} \neq x_{z, 1}$ party $i$ and $j$ gain office.

Item (1) shows that a three-party system does not necessarily lead to a bias against the common people even if the signals of the common people are not very informative. This result clearly conflicts with Proposition 1, which showed that if $\sigma p_{E}+(1-\sigma)\left(1-p_{C}\right)>\frac{1}{2}$ in a two-party system parties never cater to the interests of the common people. What causes this difference? If in a three-party system parties cater to the interests of the common people, each party wants its platform to coincide with at least one other platform. The common people use platform congruence as a criterion to determine their votes. Deviating, by catering to the interests of the elite, reduces the probability of (partial) platform congruence, and thereby decreases the chances of office. Hence, in an equilibrium where their interests are served, the common people do not need to rely on their (inferior) signals to determine what is good for them. They can use the platforms as checks. In a two-party system, such checks are not available. If platforms differ and parties have catered to the interests of one group, platforms do not provide any information. As a result, the common people have to rely on their (inferior) signals.

Item (2) adds to Proposition 2 from the previous subsection that even when traditional parties can pre-empt the entry of a populist party by moving in stage 2, an equilibrium exists with traditional parties catering to the elite in the first stage and a populist party delaying the platform choice to propose an anti-elite platform in the second. Why does party 1 not have an incentive to propose a platform in 
stage 2? Suppose that both party 1 and 3 choose a platform that deviates from party 2's platform. ${ }^{14}$ This means that the elite platform is supported by only one signal. $\alpha^{\prime \prime}$ gives the lowest value of $\alpha$ for which a member of group $C$ prefers an elite platform when the elite platform is supported by only one signal, regardless of their own private signal. Hence, for $\alpha^{\prime \prime}<\alpha<\alpha^{\prime}$, the traditional parties do not have incentives to pre-empt the populist party. For $\alpha<\alpha^{\prime \prime}$, however, party 1 has an incentive to propose a platform in stage 2. Then, only the PBE described in item (1) exists. Thus the "populist equilibrium" does not survive in the long run if $\alpha$ is too small.

Recall that in a two-party system parties cater to the interests of the elite if $\sigma p_{E}+$ $(1-\sigma)\left(1-p_{C}\right)>\frac{1}{2}$. Item $(3)$ shows that in a three-party system an equilibrium may exist in which parties cater to the interests of the elite under a less restrictive condition. This means that in a three-party system the interests of the common people are not necessarily better represented than in a two-party system.

\subsection{Experts vs. Popular Will}

The preceding section dealt with a well-known characteristic of populist policies, anti-elitism. Another populist strategy is to portray experts and specialists as allies of the elite and to emphasize one's willingness to listen to the voice of the common people instead. While relying on "popular will" for policies where the common people have superior knowledge to experts is reasonable, a particular characteristic of populist policies is to invoke popular will in policy questions where expert opinion seems superior, such as climate change or immigration policy.

Define a platform based on popular will to be populist when the opinion of even a single expert contains more information than that of the aggregate opinion of the group the platform is based upon. We show below that such a populist policy can be part of equilibrium even in our basic, two-party game. We thus offer a rationalization for the thesis put forward by, among others, Mudde (2004) that, in the last decades,

\footnotetext{
${ }^{14}$ If party 1 chooses $x_{1}=x_{2}$ in the second stage, citzens never vote for party 1 , as it has no incentive to acquire information about a state.
} 
such populist policies have been espoused also by mainstream, established political parties, in an attempt to appeal to the common people.

We extend the basic model of Section 3 to allow parties to acquire information using either of two technologies. As in the basic model, a party can base its platform on signals about the states. Each party receives one signal about $w_{E}$ and $w_{C}$ at no cost. If party $p$ bases its platform on $s_{p, j}$, we say that party $p$ relies on expert advice. Second, a party can base its platform on a poll about the opinions of members of a group as to which course of action to follow, also at no cost. Crucially, we assume that the result of the poll is observable to voters. Thus if party $p$ conducts a poll on group $j$, the entire electorate learns whether a majority of that group favors $x=0$ or $x=1$.

In reality, a poll can also lead to the wrong decision. ${ }^{15}$ To allow for such a bad outcome to happen in our model, we let policies be either normal or abnormal, $P \in\{A, N\}$. Normal policies are straightforward for voters to understand, in the sense that the probability that a citizen receives a correct signal about the state is higher than $\frac{1}{2}, p_{j}(N) \equiv \operatorname{Pr}\left(s_{i, j}=w_{j} \mid P=N\right)>\frac{1}{2}$. Abnormal policies are complex, counterintuitive and such that $p_{j}(A) \equiv \operatorname{Pr}\left(s_{i, j}=w_{j} \mid P=A\right)<\frac{1}{2} \cdot{ }^{16}$ Let $\theta$ denote the probability that a policy is normal, $\operatorname{Pr}(P=N)=\theta$. Voters are not able distinguish normal from abnormal policies. We assume that:

$$
\theta p_{j}(N)+(1-\theta) p_{j}(A)>\frac{1}{2}
$$

This equation ensures a natural interpretation of $s_{i, j}$ : For each member $i$ of group $j$, a positive signal increases the likelihood that the state is positive, while a negative signal decreases the likelihood that the state is positive. In what follows, we only consider a poll among the common people. ${ }^{17}$

\footnotetext{
${ }^{15}$ See Maskin and Tirole (2004).

${ }^{16}$ For example Dal Bó, Dal Bó and Eyster (2018) show in a laboratory experiment how voters fail to fully account for general equilibrium effects and thus may (fail to) enact welfare reducing (increasing) policies when these general equilibrium effects are important enough. Furthermore, behavioral economics has established that individuals often suffer from present bias and thus undervalue future benefits relative to present costs. Thus abnormal policies could also represent policies where this kind of bias has bite and leads to a preference reversal.

${ }^{17}$ For $p_{E}(A)=p_{C}(A)$ and $p_{E}(N)=p_{C}(N)$ conducting a poll among the elite is dominated by
} 
The requirements for a Perfect Bayesian Equilibrium of the extended model are the same as for the basic model. In addition, parties' technology choices, that is, whether to use a poll among the common people or rely on expert advice, must be optimal responses to each other and to citizens' voting strategies.

Proposition 4 Consider the basic game and allow (1) parties to use a poll among the common people to set policy; and (2) policies to be normal or abnormal.

(1) Suppose $\sigma p_{E}+(1-\sigma)\left(1-p_{C}\right)<\frac{1}{2}$. A unique equilibrium exists in which parties base their platforms on a poll among the common people if $\theta>q$, and on expert's advice regarding $w_{C}$ if $\theta \leq q$.

(2) Suppose $\sigma p_{E}+(1-\sigma)\left(1-p_{C}\right)>\frac{1}{2}$. A unique equilibrium exists in which parties base their platforms on a poll among the common people if $\theta>\alpha q+(1-\alpha)(1-q)$, and on expert advice regarding $w_{E}$, if $\theta \leq \alpha q+(1-\alpha)(1-q)$.

Item (1) of Proposition 4 shows that if the common people have electoral power (i.e. their group contains the "decisive" voter when all voters follow their signals), parties base their platforms on a poll if a poll is more informative than a single expert's opinion, $\theta>q$. To understand this result, suppose we are in an equilibrium in which both parties base their platforms on expert advice regarding $w_{C}$. Suppose party 1 deviates and conducts a poll among the common people. The deviation influences voter behavior if $x_{1} \neq x_{2}$. For a member of group $C$ the probability that party 1's policy matches $w_{C}$, given the available information, is equal to:

$$
\frac{(1-q) \theta}{(1-q) \theta+q(1-\theta)}
$$

which is higher than one half if

$$
\theta>q
$$

Thus, whenever polls aggregate more information than is contained in a single expert's opinion, the deviation is profitable and thus there can be no equilibrium in which both parties base their platforms on expert advice regarding $w_{C}$. Since in conducting a poll on the common people. For $p_{E}(A)>p_{C}(A)$ and $p_{E}(N)>p_{C}(N)$ the common people may prefer a policy based on a poll amongst the elite only if $\alpha$ is sufficiently high. Since we are especially interested in low $\alpha$ scenarios, we omit this possibility. 
that case polls are the superior technology, we do not find scope for populism as defined above in the absence of an elite bias.

Item (2) of Proposition 4 gives the conditions under which parties rely on polls or expert advice when the elite has electoral power, $\sigma p_{E}+(1-\sigma)\left(1-p_{C}\right)>\frac{1}{2}$. Suppose we are in an equilibrium in which both parties base their platforms on expert advice regarding $w_{E}$. Suppose again party 1 deviates and conducts a poll among the common people. The deviation influences voter behavior if $x_{1} \neq x_{2}$. For a member of group $C$, the probability that party 1's policy matches $w_{C}$, given the available information, is equal to:

$$
\frac{[\alpha(1-q)+(1-\alpha) q] \theta}{[\alpha(1-q)+(1-\alpha) q] \theta+[(1-\alpha)(1-q)+\alpha q](1-\theta)},
$$

which is higher than one half if

$$
\theta>\alpha q+(1-\alpha)(1-q)
$$

Note that if $\alpha=1$, this condition is equivalent to the one for the case $\sigma p_{E}+$ $(1-\sigma) p_{C}<\frac{1}{2}$. The lower is $\alpha$, the lower is the right-hand side of this inequality. Hence, the higher is the probability that the policy is distributive, the narrower is the range of parameters for which an equilibrium exists in which parties investigate states through experts.

Corollary 2 Suppose $\sigma p_{E}+(1-\sigma)\left(1-p_{C}\right)>\frac{1}{2}$. If $q>\theta>\alpha q+(1-\alpha)(1-q)$, parties follow a populist strategy in equilibrium: they rely on a poll even though more precise expert opinion on group $C$ is available.

Recall that $\theta=q$ delineates the case where a single expert opinion is equally informative as a poll. In equilibrium, if $\sigma p_{E}+(1-\sigma) p_{C}>\frac{1}{2}$ and $q>\theta>\alpha q+$ $(1-\alpha)(1-q)$, parties base their platforms on polls, while a single expert opinion (on group $C$ ) is more informative. The use of an inefficient technology is a response to the bias towards the elite identified in Section 4. Given this bias, voters anticipate correctly, that, whenever parties rely on experts, such expertise is about the state of the world the elite cares about. There is thus a range of parametres for which the common people prefer a platform based on a poll to one based on expert opinion 
about $w_{E}$, even though experts are individually better informed than the common people as a group: $q>\theta$. This range of parameters is also larger the smaller is $\alpha$ and thus the less likely it is that the groups' interests are aligned.

Proposition 4 thus helps to explain why not only populists, but also mainstream parties may follow a populist strategy: rely on the opinion of the common people even when it is common knowledge that experts are better informed. It is worth emphasizing that for such an outcome to be part of equilibrium, we need voters to observe the outcomes of polls, and polls to be conducted among the members of one group only. A poll aggregating everyone's preferences, that is, a referendum, would feature again an elite bias if $\sigma p_{E}+(1-\sigma) p_{C}>\frac{1}{2}$. In practice, operationalizing the concept of the "common people" is not trivial and leaves parties with a certain leeway in how exactly to conduct the poll. If commitment on investigating a certain group would not be possible through polling, the bias in favour of the elite would materialize again. Thus the institutional specificities of a country, for example independent and neutral pollsters, will determine the feasibility of polls as a commitment device.

\section{Discussion}

This paper provides an explanation for the widespread emergence of two populist traits: anti-elite platforms and platforms based on popular will when superior expert opinion is available. We have argued that the emergence of both traits is a response to a bias of elections towards more knowledgeable citizens. While populist platforms are based on inferior information - parties proposing an anti-elite platform do not use any information and platforms based on popular will are populist when they rely on a signal that is less informative than that of an expert - the common people expect to benefit from them.

A necessary condition for an electoral bias towards the elite is that knowledge beats numbers, i.e. $\sigma p_{E}+(1-\sigma)\left(1-p_{C}\right)>\frac{1}{2}$. Once this condition is violated, for example if $p_{C}$ is increased sufficiently, parties cater to the interests of the common

people, the best outcome for the common people. If $\sigma p_{E}+(1-\sigma)\left(1-p_{C}\right)>\frac{1}{2}$ and 
$\alpha<\frac{1}{2}$, the common people benefit from an anti-elite platform. Proposition 2 and 3 show that given $\sigma p_{E}+(1-\sigma)\left(1-p_{C}\right)>\frac{1}{2}$, an increase in $p_{C}$ may prevent entry of a party with an anti-elite platform. The reason is that an anti-elite platform is only viable if it induces the common people to vote for it with a united front. A sufficiently high value of $p_{C}$ breaks the united front. Hence, in a world where numbers lose to knowledge, the common people may suffer from becoming more knowledgeable.

We now assume that $\sigma p_{E}+(1-\sigma)\left(1-p_{C}\right)>\frac{1}{2}$, and examine how changes in $\alpha$ and $q$ influence the emergence of populist traits. The lower is $\alpha$, the more the common people suffer from an electoral bias towards the elite. The intuition is straightforward. The lower is $\alpha$, the higher is the probability that the interests of the elite and the common people diverge and the more likely elite platforms hurt the common people. Proposition 2 shows that entry of a third party with an antielite platform requires that $\alpha<\alpha^{\prime}<\frac{1}{2}$. Corollary 2 shows that a lower value of $\alpha$ also gives broader scope for platforms based on popular will. Recent empirical studies find that the current rise in populist policies coincides with globalization and ensuing labor and capital mobility. Increased factor mobility probably increased the cost of redistribution from the more mobile elite towards the common people (see e.g. Egger et al., 2019, for the influence of globalization on labor income taxation systems). The latter could be understood as a decrease in $\alpha$. Our model thus offers an explanation why individuals that were hurt by globalization and other important adverse shocks find it easier to turn towards populists leaders nowadays (see e.g. Guiso et al., 2019).

Maybe most surprisingly, our model predicts that better-informed parties broaden the scope for populist entry. Intuitively, anti-elite platforms derive their credibility from the information contained in the platforms of the traditional parties, which cater to the interests of the elite. This information is more persuasive, when $q$ goes up. In a three-party system, for high values of $q$ all parties have incentives to offer anti-elite platforms. As, by definition, anti-elite platforms require the existence of elite platforms, anti-elitism cannot be a equilibrium outcome. An equilibrium does exist in which parties cater to the interest the common people. Hence, also in a three- 
party system the common people may benefit from high values of $q \cdot{ }^{18}$ Our finding that better informed traditional parties may raise the suspicion of the common people is related to de Moragas (2017), who studies how voters react to expert agreement. He shows that broad consensus among experts signals that experts probably share a common bias and that their advice is not in the voters' interest. Thus politicians basing their platforms on these experts' advice receive less support from the electorate. Also in our setting expert agreement (i.e. platform convergence) encourages populist/anti-elite policies. In contrast to de Moragas (2017), where the bias is exogenous, in our setting the bias arises endogenously from political competition.

Our results are derived from a model that is based on many assumptions. We elaborate on five important ones. First, we have assumed that society consists of two groups, the elite and the common people. Separating society in two homogenous groups is often seen as a main feature of populism (see for example Mudde, 2004; Guriev and Papaioannou, 2020). Therefore, a more comprehensive theory of populism would explain this feature rather than assume it. In our basic model, the common people do not act as a homogenous group. On the contrary, the electoral bias towards the elite results from a higher dividedness of the common people. The source of this dividedness is lack of information. Delli Carpini and Keeter (1996) have examined the knowledge of voters of different groups of parties' positions on key policy questions. They found that less educated and lower income voters possess less such knowledge. Of course, this does not mean that limited knowledge is the only reason for dividedness of the common people. Another possible reason is that the "common people" consist of a variety of groups with different interests. When the common people consist of $n>1$ groups, whose members all have limited knowledge of how the project affects them, the bias towards the elite may survive. To see this in the simplest way, suppose that all members of each group $j$ in $n$ receive

\footnotetext{
${ }^{18}$ Corollary 2 shows that parties with access to better informed experts are also more inclined to turn to a platform based on popular will even though based on inferior information. The reason is partly mechanical. The better experts are informed, the inferior public opinion polls become in comparison and thus the more likely we categorize a platform based on polls as populist.
} 
uninformative signals, $p_{C_{j}}=\frac{1}{2}$. Then, $\sigma p_{E}+\frac{1}{2}(1-\sigma)>\frac{1}{2}$ share of the electorate votes for the platform that benefits the elite. As the common people is not an homogenous group, there are winners and losers under the common people. If $\alpha_{j}<\frac{1}{2}$, that is members of group $j$ expect to suffer from an elite platform, anti-elitism may emerge again.

Second, in our model the elections revolve around a policy with possibly distributive consequences. In theory, once the policy effects have been realized, the winners could compensate the losers. For many types of policies this is difficult, for example, because their effects are highly uncertain and only felt in the long term. For others, compensation is in principle possible (at some cost). An interesting question for future research is whether, when compensation is feasible, the electoral bias towards the elite is reinforced. In other words, will the elite be compensated more often than the common people in case that they end up suffering from the implemented policy?

A third important assumption is that in our models parties solely care about winning the elections. We did not allow parties to care about the effects of policies on "their" groups. Our model shows that for ideology to work for the common people, trust is key: People should vote for their party even when this party offers a platform that is detrimental to their own private views. One contribution of our paper is that it shows that it is not easy to win and maintain the trust of the common people. Once a party has the confidence of the people, moral-hazard problems arise. A measure of trust in parties is party membership. Interestingly, in many western democracies party membership has been rapidly declining in the past centuries (see e.g. van Biezen et al., 2012, for Europe). Why this has happened goes beyond the scope of our paper - we leave it for future research.

A fourth important assumption is that the signal a party receives is not observable to voters. Rather than consulting party experts, a politician may consult an independent advisory institution. Such recommendations may then be observable to the public. Two situations are possible 1) while the recommendation itself is publicly observable, it is not observed whether it is based on a signal about the elite or the common people, 2) the recommendation is observed and it is observed whether it is based on the signal about the common people or the elite. Note that 
only in the latter case, the elite bias will disappear.

Finally, our model describes only one election. We have shown that in such a static setting, anti-elite platforms are not chosen in a two-party system. In a dynamic model, covering multiple elections, anti-elite platforms may also emerge in two-party systems. This requires that parties' platforms of previous elections contain information what is good for the common people in later elections. ${ }^{19}$ Whether in such an extended model populist policies are provided through traditional parties or newcomers is an interesting question beyond the scope of this paper. ${ }^{20}$

\footnotetext{
${ }^{19}$ A recent paper on extremism, Eguia and Giovannoni (2019), also focuses on intertemporal strategic choices in two-party electoral competition. By moving away from mainstream policies a weak party incurs electoral costs in the short run but at the same time builds a reputation in extreme policies that may be rewarded with higher electoral success in the long run. In our setting, a "populist" party does not gain a reputation but is given credibility solely through the actions and knowledge of the traditional party.

${ }^{20}$ Buisseret and van Weelden (2020) offer a theoretical model to shed light on the question in which situations challengers enter competition as third-parties and when through the primaries of established parties.
} 


\section{References}

Acemoglu, D., Egorov, G. \& Sonin, K. (2013), 'A Political Theory of Populism', The Quarterly Journal of Economics 128(2), 771-805.

Agranov, M., Eilat, R. \& Sonin, K. (2020), 'A Political Model of Trust'. BFI working paper 2020-50, University of Chicago.

Algan, Y., Guriev, S., Papaioannou, E. \& Passari, E. (2017), 'The European Trust Crisis and the Rise of Populism', Brookings Papers on Economic Activity .

Autor, D., Dorn, D., Hanson, G. \& Majlesi, K. (2016), 'Importing Political Polarization? The Electoral Consequences of Rising Trade Exposure'. NBER Working paper Nr. 22637.

Bernhardt, D., Krasa, S. \& Shadmehr, M. (2019), 'Demagogues and the Fragility of Democracy'. working paper.

Biezen, van, I., Mair, P. \& Poguntke, T. (2012), 'Going, Going,...Gone? The Decline of Party Membership in Contemporary Europe', European Journal of Political Research 51(1), 24-56.

Broockman, D. E. \& Skovron, C. (2018), 'Bias in Perceptions of Public Opinion Among Political Elites', American Political Science Review 112(3), 542-563.

Buisseret, P. \& Van Weelden, R. (2019), 'Crashing the Party? Elites, Outsiders, and Elections', American Journal of Political Science .

Colantone, I. \& Stanig, P. (2018a), 'Global Competition and Brexit', American Political Science Review 112(2), 201-218.

Colantone, I. \& Stanig, P. (2018b), 'The Trade Origins of Economic Nationalism: Import Competition and Voting Behavior in Western Europe', American Journal of Political Science 62(4), 936-953. 
Dal Bó, E., Dal Bó, P. \& Eyster, E. (2018), 'The Demand for Bad Policy When Voters Underappreciate Equilibrium Effects', The Review of Economic Studies $\mathbf{8 5}(2), 964-998$.

Dal Bó, E., Finan, F., Folke, O., Persson, T. \& Rickne, J. (2019), 'Economic Losers and Political Winners: Sweden's Radical Right'. mimeo.

de Moragas, A.-I. (2017), 'When Consensus Hurts: Experts' Advice and Electoral Support'. mimeo.

Delli Carpini, M. X. \& Keeter, S. (1996), What Americans Know About Politics and Why It Matters, Yale University Press.

Di Tella, R. \& Rotemberg, J. J. (2018), 'Populism and the Return of the "Paranoid Style": Some Evidence and a Simple Model of Demand for Incompetence as Insurance Against Elite Betrayal', Journal of Comparative Economics 46(4), 988-1005.

Dornbusch, R. \& Edwards, S. (1991), The Macroeconomics of Populism in Latin America, University of Chicago Press.

Egger, P. H., Nigai, S. \& Strecker, N. M. (2019), 'The Taxing Deed of Globalization', American Economic Review 109(2), 353-90.

Eguia, J. X. \& Giovannoni, F. (2019), 'Tactical Extremism', American Political Science Review 113(1), 282-286.

Foster, C. \& Frieden, J. (2017), 'Crisis of Trust: Socio-Economic Determinants of Europeans' Confidence in Government', European Union Politics 18(4), 511535.

Gennaioli, N. \& Tabellini, G. (2019), 'Identity, Beliefs, and Political Conflict', SSRN Electronic Journal .

Gilens, M. \& Page, B. I. (2014), 'Testing Theories of American Politics: Elites, Interest Groups, and Average Citizens', Perspectives on Politics 12(3), 564581. 
Guiso, L., Herrera, H., Morelli, M. \& Sonno, T. (2019), 'Global Crises and Populism: The Role of Eurozone Institutions', Economic Policy 34(97), 95-139.

Guriev, S. \& Papaioannou, E. (2020), 'The Political Economy of Populism'. SSRN working paper, available at https://ssrn.com/abstract $=3542052$.

Inglehart, R. \& Norris, P. (2017), 'Trump, Brexit, and the Rise of Populism: Economic Have-Nots and Cultural Backlash', SSRN Electronic Journal .

Kalla, J. L. \& Porter, E. (2020), 'Correcting Bias in Perceptions of Public Opinion Among American Elected Officials: Results From Two Field Experiments', British Journal of Political Science pp. 1-9.

Levy, G., Razin, R. \& Young, A. (2020), 'Misspecified Politics and the Recurrence of Populism'. working paper.

Louwerse, T. \& Otjes, S. (2019), 'How Populists Wage Opposition: Parliamentary Opposition Behaviour and Populism in Netherlands', Political Studies 67(2), 479-495.

Maskin, E. \& Tirole, J. (2004), 'The Politician and the Judge: Accountability in Government', American Economic Review 94(4), 1034-1054.

Morelli, M., Nicoló, A. \& Roberti, P. (2020), 'Populism as Simplistic Commitment'. Manuscript. Bocconi University.

Mudde, C. (2004), 'The Populist Zeitgeist', Government and Opposition 39(4), 541563.

Nai, A. (2018), 'Fear and Loathing in Populist Campaigns? Comparing the Communication Style of Populists and Non-Populists in Elections Worldwide', Journal of Political Marketing pp. 1-32.

Noury, A. \& Roland, G. (2020), 'Identity Politics and Populism in Europe', Annual Review of Political Science 23(1), 421-439. 
Panunzi, F., Pavoni, N. \& Tabellini, G. (2020), 'Economic Shocks and Populism: The Political Implications of Reference-Dependent Preferences'. IGIER Working Paper n. 670.

Rodrik, D. (2018), 'Populism and the Economics of Globalization', Journal of International Business Policy 1(1-2), 12-33.

Schakel, W. \& van der Pas, D. (2020), 'Degrees of Influence: Educational Inequality in Policy Representation', European Journal of Political Research .

Stiglitz, J. E. (2002), Globalization and Its Discontents, W.W. Norton. 


\section{Appendix}

\subsection{Proof of Lemma 1}

In equilibrium, voters infer the signal $s_{p, j}$ a party $p$ bases their platform on. Without loss of generality (because of symmetry), assume that $s_{1, j}=1$ and $s_{2, k}=-1$, $j, k \in\{E, C\}$. Voter $i$ of group $j$ votes in line with her signal if and only if $\operatorname{Pr}\left(w_{j}=s_{i, j} \mid s_{1, j}, s_{2, k}, s_{i, j}\right)>\frac{1}{2}$, for both $s_{i, j}=1$ and $s_{i, j}=-1$. There are two cases. First, suppose parties cater to the same group: $k=j$. Then, $\operatorname{Pr}\left(w_{j}=s_{i, j} \mid 1,-1, s_{i, j}\right)=$ $p_{j}>\frac{1}{2}$, implying that voter $i$ of group $j$ follows her signal. Second, $k \neq j$. Then, $\operatorname{Pr}\left(w_{j}=1 \mid 1,-1,1\right) \geq p_{j}>\frac{1}{2}$, implying that citizen $i$ follows her signal if $s_{i, j}=s_{1, j}$. Furthermore, voter $i$ of group $j$ follows her signal when it conflicts with $s_{i, j}$ if

$$
\begin{aligned}
& \operatorname{Pr}\left(w_{j}=1 \mid-1,1,1\right) \\
= & \frac{p_{j}\left[\alpha q(1-q)+(1-\alpha)(1-q)^{2}\right]}{p_{j}\left[\alpha q(1-q)+(1-\alpha)(1-q)^{2}\right]+\left(1-p_{j}\right)\left[\alpha q(1-q)+(1-\alpha) q^{2}\right]}>\frac{1}{2},
\end{aligned}
$$

implying

$$
\alpha>\frac{(2 q-1) p_{j}-\left(2 p_{j}-1\right) q^{2}}{(2 q-1)\left(p_{j}+q-2 p_{j} q\right)} \equiv \widehat{\alpha}\left(p_{j}\right) .
$$

Thus for $\alpha \geq \hat{\alpha}\left(p_{j}\right)$ voter $i$ of group $j$ follows her signal. For $\alpha<\widehat{\alpha}\left(p_{j}\right)$ voter $i$ of group $j$ votes for party 1 even if $s_{i, j} \neq s_{1, j}$. So, if $\alpha<\widehat{\alpha}\left(p_{j}\right)$ members of group $j$ vote with a united front for party 1 .

\subsection{Proof of Proposition 1}

We prove Proposition 1 in three steps. First we show that there exists no equilibrium in which the group of the decisive voter votes with a united front in case $x_{1} \neq x_{2}$. Second we show that if the group of the decisive voter follows their private signals when $x_{1} \neq x_{2}$, it is a dominant strategy for a party to base its platform on the signal of that group. Finally, we show that the value of $\sigma p_{E}+(1-\sigma)\left(1-p_{C}\right)$ determines which signal both parties want to use to set their platforms.

Suppose the group of the decisive voter votes with a united front in case $x_{1} \neq x_{2}$. In that case either party 1 or party 2 must win with certainty when $x_{1} \neq x_{2}$. When $x_{1}=x_{2}$, parties always tie. This immediately implies that both parties want to base 
their platform on a signal. The "losing party" wants to use the same signal as the "winning party" to maximize the chance of a tie, while the "winning party" wants to use the same signal as the "losing party" and invert it, to maximize the chance of conflicting platforms. This implies that there cannot be such an equilibrium where the group of the decisive voter votes with a united front when $x_{1} \neq x_{2}$.

Next, consider the case where the group of the decisive voter follows their signals when given the choice between both platforms. When $x_{1}=x_{2}$, parties tie. In that case it is a dominant strategy for each party to base their platform on the signal of this group as this maximizes the chance of winning. This implies that in any equilibrium both parties base their platform on the same signal and thus both groups always follow their private signals when $x_{1} \neq x_{2}$.

Finally, to determine the group of the decisive voter, note that a share $\sigma p_{E}+$ $(1-\sigma)\left(1-p_{C}\right)$ of the citizens vote for the platform that is in the interest of the elite, and share $\sigma\left(1-p_{E}\right)+(1-\sigma) p_{C}$ of the citizens vote for the platform that is

in the interest of the common people. This means that if $\sigma p_{E}+(1-\sigma)\left(1-p_{C}\right)>\frac{1}{2}$ the decisive voter belongs to the elite while if $\sigma p_{E}+(1-\sigma)\left(1-p_{C}\right)<\frac{1}{2}$ the decisive voter belongs to the common people.

\subsection{Proof of Proposition 2}

We first prove two lemmas that imply that party 3 will never buy a costly signal in equilibrium.

The group that the decisive voter belongs to is known to all. As party 3 is moving second, in equilibrium it observes $x_{1}$ and $x_{2}$ and has correct beliefs about which signals these are based on. Party 3 buys a signal only if it improves its chances of winning. This can only be the case when the expected payoff associated to at least one possible platform choice, $x_{3}=1$ or $x_{3}=0$, depends on one of the underlying states. This can only happen if the decisive voter is following her signal. In this case the signal party 3 should use is about the state that is relevant for the decisive voter. This implies Lemma 2 hereafter. 
Lemma 2 In equilibrium, party 3 never bases its platform on its signal regarding $w_{C}$ if $\sigma p_{E}+(1-\sigma)\left(1-p_{C}\right)>\frac{1}{2}$, and never on $w_{E}$ if $\sigma p_{E}+(1-\sigma)\left(1-p_{C}\right)<\frac{1}{2}$.

Now suppose that party 3 bases its platform on a signal about the state relevant for the group of the decisive voter. Then, members of that group may follow their signals when voting only if they are in one of the following scenarios:

a) only one traditional party relies on a signal about the state of the world relevant to the decisive group (two subcases are possible, depending on whether the second traditional party uses a signal about the other state or remains uninformed);

b) only one traditional party relies on a signal, the signal is about the state of the world that is not relevant for the decisive voter and $\alpha$ is close to 0 or 1 ; or

c) both traditional parties rely on a signal about the state of the world that is not relevant to the decisive voter.

Remark that this also rules out immediately equilibria in which all parties use a signal on the same group. Whether $x_{i}=x_{j}=x_{k}$ or $x_{i} \neq x_{j}=x_{k}$, voters never find it optimal to follow their signals in that case. We show now that none of the scenarios listed above is consistent with equilibrium.

Consider case a1): Only one traditional party uses a signal, about the state of the world relevant to the decisive group. Say it is party 1. In this proposed equilibrium, the uninformed party 2 never receives any votes and the expected payoff of party 3 is one half. But the entrant can achieve this payoff without buying signals by just setting its platform equal to that of the informed traditional party.

Now consider case a2): party 1, say, bases its platform on a signal about the state of the world relevant to the decisive group and party 2 bases its platform on a signal of the other group. In this case, voters of the decisive group follow signals when the entrant and the traditional party catering to the same group offer conflicting platforms. When $x_{1}=x_{3}$, party 2 receives a positive payoff only if $x_{2}=x_{1}=x_{3}$. This is most likely if it bases its platform on the same signal as the other parties. Thus party 2 has a profitable deviation and prefers to base its platform on the same signal as the other parties. An analogous reasoning can be applied in case a traditional party inverts the signal it acquires. Therefore, we can rule out cases a1 
and a2.

Consider case b). The argument is analogous to that of a1 and thus we can rule it out too. This is also true in case $\alpha$ is close to 0 and the traditional party inverts its signal.

Consider case c). If the traditional parties put forth conflicting platforms, the decisive group ignores their signals and always supports the entrant if they believe the entrant bought a signal. But then this signal acquisition by the entrant is not credible. Thus traditional parties both win with chance one half. If traditional parties put forth the same platform, and $\alpha$ is such that if the entrant comes in with a conflicting platform that is believed to be based on a signal, the pivotal voter follows her signal, the entrant will also win some of the time. But then traditional parties want to minimize the chance that they end up offering the same platform, so we cannot have case c) in equilibrium either. Again, the same conclusion is reached if we let parties base their platform on an inverted signal. We thus have proven the following.

Lemma 3 There does not exist an equilibrium where party 3, upon observing $x_{1}$ and $x_{2}$, acquires information, enters and bases its platform on a signal. In any equilibrium, upon entry, party 3 will only base its platform on $x_{1}$ and $x_{2}$.

Now consider parties 1 and 2. They anticipate the best response of the entrant. Analogously to the proof of Proposition 1 we first exclude equilibria where the group of the decisive voter does not follow their private signals if $x_{1} \neq x_{2}$. First consider the case where voters believe that both traditional parties acquired information. In that case they each earn one half or zero in case $x_{1}=x_{2}$. We can apply the exact same argument to exclude any case where each traditional party earns one half whenever $x_{1}=x_{2}$. If both traditional parties receive zero whenever $x_{1}=x_{2}$, one traditional party is always losing, no matter what platform it puts forth and has no incentive to acquire information. Finally, if voters believe only one traditional party acquired information, this party's payoff is independent of the underlying states and thus it has no incentive to actually aquire information.

Now consider the case where the group of the decisive voter follows their private 
signals. Denote by $\lambda(\gamma)$ the probability that traditional party $i(j)$ puts forth the platform consistent with the state of the decisive group. We will show that regardless of the behavior of the entrant (which does not base its platform on a signal) and the other party (who may), it is a dominant strategy for party $i$ to maximize the chance that it offers the platform that is consistent with the state of this group.

First consider the case where voters believe no party bases their platform on information. Then the expected payoff of party $i$ when party 3 enters only if $x_{1}=x_{2}$ and chooses $x_{3}=x_{i}$ equals

$$
\lambda\left(\frac{\gamma}{3}+(1-\gamma)\right)+\frac{(1-\lambda)(1-\gamma)}{3} .
$$

The expected payoff of party $i$ when party 3 enters only if $x_{1}=x_{2}$ and chooses $x_{3} \neq x_{i}$ equals

$$
\lambda\left(\frac{\gamma}{2}+(1-\gamma)\right)
$$

The expected payoff of party $i$ when party 3 enters only if $x_{1} \neq x_{2}$ and chooses $x_{3}=x_{i}$ equals

$$
\lambda\left(\frac{\gamma}{2}+\frac{(1-\gamma)}{2}\right)+\frac{(1-\lambda)(1-\gamma)}{2} .
$$

The expected payoff of party $i$ when party 3 enters only if $x_{1} \neq x_{2}$ and chooses $x_{3} \neq x_{i}$ equals

$$
\lambda\left(\frac{\gamma}{2}+(1-\gamma)\right)+\frac{(1-\lambda)(1-\gamma)}{2}
$$

As all these payoffs are increasing in $\lambda$ we conclude that at least one traditional party needs to acquire and use the signal in equilibrium.

Now consider the case in which voters believe that party $j$ acquired information, while $i$ did not. The expected payoff of party $i$ when party 3 enters only if $x_{1}=x_{2}$ or only if $x_{1} \neq x_{2}$ and chooses $x_{3} \neq x_{i}$ equals

$$
\lambda(1-\gamma)
$$

whereas, when party 3 enters only if $x_{1} \neq x_{2}$ and chooses $x_{3}=x_{i}$, the expected payoff is given by:

$$
\lambda\left(\frac{(1-\gamma)}{2}\right)
$$


Again both payoffs increase with $\lambda$ and thus party $i$ also wants to buy a signal. So both traditional parties need to acquire information in equilibrium.

Thus, now assume that indeed both traditional parties acquire information. This immediately implies that entry never occurs if $x_{1} \neq x_{2}$. Furthermore, when $x_{1}=x_{2}$ entry can only be successful if $x_{3} \neq x_{1}$.

We have already shown that the expected payoff is increasing in $\lambda$ when there is no entry and voters follow their private signals if $x_{1} \neq x_{2}$. The expected payoff of party $i$ when party 3 enters succesfully only if $x_{1}=x_{2}$ and chooses $x_{3} \neq x_{i}$, while voters follow their private signals is

$$
\lambda(1-\gamma)
$$

which again is increasing in $\lambda$. Thus both parties invest in a signal about the state of the world relevant to the decisive group.

Finally, we need to determine the conditions under which party 3 successfully enters. When the traditional parties cater to group $C$, it will never be profitable to enter, as group $E$ is the minority. On the other hand, when the traditional parties cater to group $E$, entry may be successful. Let us thus consider the voters of group $C$. In the prescribed equilibrium where entry is succesful, a member of group $C$ votes for party 3 irrespective of her signal if $x_{3} \neq x_{1}=x_{2}$. Hence, if a member of group $C$ receives signal $s_{i, C}=1$ if $x_{1}=x_{2}=1$ or $s_{i, C}=-1$ if $x_{1}=x_{2}=0$ her updated beliefs must be such that she does not follow her signal but instead votes for party $3 .^{21}$ This requires that

$$
\frac{\left(\alpha q^{2}+(1-\alpha)(1-q)^{2}\right) p_{C}}{\left(\alpha q^{2}+(1-\alpha)(1-q)^{2}\right) p_{C}+\left((1-\alpha) q^{2}+\alpha(1-q)^{2}\right)\left(1-p_{C}\right)}<\frac{1}{2},
$$

meaning

$$
\alpha<\alpha^{\prime} \equiv \frac{q^{2}-p_{C}(1-2(1-q) q)}{2 q-1}
$$

Summarizing, we have shown that the traditional parties always base their platform on the group that contains the decisive voter. Entry will occur if this group is the elite, the traditional parties agree on their platforms and $\alpha<\alpha^{\prime}$.

\footnotetext{
${ }^{21}$ Clearly, if $s_{i, C}=x_{3}$, member $i$ of group $C$ is more inclined to vote for party 3 than if $s_{i, C} \neq x_{3}$.
} 


\subsection{Proof Proposition 3}

\subsubsection{Proof of Item 1.}

We first study optimal voter beliefs and behavior given that parties behave as prescribed in Item 1. Consider voter $i$ of group $C$. Suppose $s_{i C}=x_{1,1}=x_{2,1} \neq x_{3,1}$, then voter $i$ votes for either party 1 or 2 . Suppose now that $x_{1,1}=x_{2,1} \neq x_{3,1}=s_{i C}$. As $p_{C}<q$, voter $i$ still votes for parties 1 and 2 . Indeed, $i$ 's posterior beliefs about $s_{i C}\left(\right.$ and $\left.x_{3,1}\right)$ being correct are given by:

$$
\frac{p_{C} q(1-q)^{2}}{p_{C} q(1-q)^{2}+\left(1-p_{C}\right)(1-q) q^{2}}<\frac{1}{2}
$$

Thus any voter of group $C$ always votes for parties 1 or 2 if $x_{1,1}=x_{2,1} \neq x_{3,1}$.

We now study parties' possible deviations from their prescribed strategy. First, does any party have an incentive to propose a platform in stage 2? Such a move can generate a non-zero probability of winning only if the deviant is believed to have based its platform on a signal about $w_{C}$. Indeed, voters believe that the two parties which follow the prescribed strategy base their platforms on their signals about $w_{C}$ as these two parties could not anticipate the deviation by the other party. In case the platforms of these two parties are equal, the deviant party can receive a positive payoff only when if it chooses the same platform and this platform is believed to be based on a signal about $w_{C}$. Yet, as soon as voters believe this, the deviant can improve further on its payoff if it does not buy the signal about $w_{C}$. In case the two non-deviating parties propose different platforms, the deviant party has no incentive to actually acquire and use costly information. Thus, it is not profitable to deviate to moving in the second stage with a platform based on a signal about $w_{C}$.

Does any party have an incentive to not base its platform on $w_{C}$ ? To gain office, a party should propose a platform that at least one other party also proposes. Given that the other two parties base their platforms on their signals about $w_{C}$, a party maximizes the probability of "platform congruence" by also basing its platform on $w_{C}$. Thus a deviation to investigating $w_{E}$, not investigating or inverting on of the two signals is also not profitable. 


\subsubsection{Proof of Item 2.}

First of all, remark that the restrictions imposed on the values $\alpha$ can take on $\frac{q-p_{C}}{2 q-1} \equiv \alpha^{\prime \prime}<\alpha<\alpha^{\prime} \equiv \frac{q^{2}-p_{C}(1-2(1-q) q)}{2 q-1}$ - are meaningful as $\frac{q-p_{C}}{2 q-1}$ is always (weakly) smaller than $\frac{q^{2}-p_{C}(1-2(1-q) q)}{2 q-1}$ given that $p_{C}<q \leq 1$.

Given the above restrictions, party 3's prescribed strategy and the fact that $\sigma p_{E}+(1-\sigma)\left(1-p_{C}\right)>\frac{1}{2}$, the parties that move in stage 1 do not have an incentive to deviate. Indeed, consider first a deviation to stage 2 by party 1, say. Since party 1 observes party 2's platform and party 3's platform is also based on party 2's platform, party 1 cannot credibly deviate to stage 2 with a platform based on a costly signal. Thus upon deviation, party 1 announces $x_{1,2} \neq x_{2,1}$. Party 3's best response to this deviaton - party 3 observes that party 1 did not move in stage 1 - is also to announce $x_{3,2} \neq x_{2,1}$ after no investigation. To sustain the prescribed equilibrium, the common people should not vote for party 1 and party 3 with a united front. Consider the beliefs of a voter of group $C$ who received a signal equal to $x_{2,1}$. This voter finds it optimal to follow her signal when:

$$
\frac{(\alpha q+(1-\alpha)(1-q)) p_{C}}{(\alpha q+(1-\alpha)(1-q)) p_{C}+((1-\alpha) q+\alpha(1-q))\left(1-p_{C}\right)}>\frac{1}{2},
$$

which implies

$$
\alpha>\alpha^{\prime \prime} \equiv \frac{q-p_{C}}{2 q-1} .
$$

When the above holds, party 1 and 2 have no incentives to deviate to stage 2 .

The proof of Proposition 2 implies that, given the prescribed equilibrium, party 1 or 2 also have no incentive to deviate in the current stage from basing their platform on a signal about $w_{E}$.

Now consider deviations by party 3. First note that we have shown in the proof of Proposition 2 that it is not rational for party 3 to enter in stage 2 with a platform based on one of the costly signals. The same argument holds in this setting for party 3 acquiring information when moving in stage 2 . This implies that in a situation where $x_{11} \neq x_{21}$ the third party never receives any votes because voters prefer informed parties and it thus sets a platform randomly. Setting the anti-elite platform after $x_{11}=x_{21}$ is an optimal strategy whenever it ensures party 3 wins at least with 
some positive probability. This is the case whenever $\alpha<\alpha^{\prime} \equiv \frac{q^{2}-p_{C}(1-2(1-q) q)}{2 q-1}$ as then all group $C$ voters vote for party 3 with a united front.

Does party 3 have any incentive to deviate to stage 1? If voters believe party 3 did not acquire and use any signal in its platform, this deviation is not profiable. Suppose now voters believe party 3 based its platform on a signal about $w_{E}$. Its expected payoff is then $1 / 3$. Following its prescribed strategy yields an expected payoff of $q^{2}+(1-q)^{2}>1 / 3$ and thus this deviation is also not profitable. Finally, party 3 could win if voters believed it based its platform on a signal about $w_{C}$. If voters would indeed hold such beliefs party 3 would instead invert the signal about $w_{E}$ to maximize the chance of platform incongruence. Thus it is not rational for voters to believe ithe deviant based its platform on a signal about $w_{C}$. Thus such a deviation is not profitable.

\subsubsection{Proof of Item 3.}

We first need to ensure that a majority of voters always back the two congruent parties in case one of the three platforms is not equal to the other two. Suppose $x_{1,1}=x_{2,1} \neq x_{3,1}$. Then no member of the elite votes for party 3 , because $q \geq p_{E}$ by assumption. If $\sigma+(1-\sigma)\left(1-p_{C}\right)>\frac{1}{2}$, parties 1 and 2 can secure a majority of the votes if all members of group $C$ vote in line with their signal. A member of group $C$ who received a signal that is equal to $x_{3,1}$ votes for $x_{3,1}$ if and only if

$$
\begin{gathered}
\frac{p_{C}\left[\alpha(1-q)^{2} q+(1-\alpha) q^{2}(1-q)\right]}{p_{C}\left[\alpha(1-q)^{2} q+(1-\alpha) q^{2}(1-q)\right]+\left(1-p_{C}\right)\left[\alpha(1-q) q^{2}+(1-\alpha) q(1-q)^{2}\right]}>\frac{1}{2} \\
\Longleftrightarrow \alpha<\frac{p_{C}+q-1}{2 q-1} .
\end{gathered}
$$

A group $C$ member who received a signal equal to $x_{1,1}$ and $x_{2,1}$ votes for either party 1 or 2 if and only if

$$
\begin{gathered}
\frac{p_{C}\left[\alpha(1-q) q^{2}+(1-\alpha) q(1-q)^{2}\right]}{p_{C}\left[\alpha(1-q) q^{2}+(1-\alpha) q(1-q)^{2}\right]+\left(1-p_{C}\right)\left[\alpha(1-q)^{2} q+(1-\alpha) q^{2}(1-q)\right]}>\frac{1}{2} \\
\Longleftrightarrow \alpha>\frac{q-p_{C}}{2 q-1} .
\end{gathered}
$$

Together, the conditions one needs to impose on posterior beliefs for group $C$ voters to follow their signal thus require $\alpha$ must be such that: $\frac{q-p_{C}}{2 q-1}<\alpha<\frac{q+p_{C}-1}{2 q-1}$. 
Also, if all members of group $C$ vote for 1 or 2 , the prescribed equilibrium could exist. This requires $\alpha>\frac{q+p_{C}-1}{2 q-1}$.

Next, we need to ensure that a deviation by a party to basing its platform on a signal about $w_{C}$ is not profitable. Given that this deviation is not observable by voters, the effect of such a deviation is only to increase the chances that the deviant's platform ends up not agreeing with the other two platforms when these two match each other. And in this case voters do not vote for the deviant. Thus this deviation is not profitable. More generally, any deviation away from basing the platform on the signal on $w_{E}$ is dominated.

We also need to ensure that a deviation to stage 2 is not profitable. Suppose that party 1 and 2 follow the prescribed strategy and party 3 deviates to moving in stage 2. We know from the proof of Proposition 2 that, given the equilibrium strategies of party 1 and 2 , it is not rational for the third party to acquire and use a signal. If $x_{1,1}=x_{2,1}$, the third party must thus propose $x_{3,2} \neq x_{1,1}$ in stage 2. For group $C$ voters to not be willing to vote for party 3 we need to impose that $\alpha>\alpha^{\prime} \equiv \frac{q^{2}-p_{C}(1-2(1-q) q)}{2 q-1}<1 / 2$; see the proof of Item (2). Remark now that $\frac{q+p_{C}-1}{2 q-1}$ is increasing in $p_{C}$, decreasing in $q$ and is equal to at least $1 / 2$. Thus $\frac{q+p_{C}-1}{2 q-1}>\frac{q^{2}-p_{C}(1-2(1-q) q)}{2 q-1}$. For the equilibrium described in Item (3) to exist we need to impose that either that $\alpha \geq \frac{q+p_{C}-1}{2 q-1}$, for which the constraint $\alpha>\alpha^{\prime}$ does not bind, or that $\frac{q-p_{C}}{2 q-1}<\alpha<\frac{q+p_{C}-1}{2 q-1}$ (and $\sigma+(1-\sigma)\left(1-p_{C}\right)>\frac{1}{2}$ ) for which the constraint $\alpha>\alpha^{\prime}$ actually binds. Thus, in the latter case, we need to impose that

$\alpha$ takes on values between $\frac{q^{2}-p_{C}(1-2(1-q) q)}{2 q-1}$ and $\frac{q+p_{C}-1}{2 q-1}$. This concludes the proof of the last Item of Proposition 3.

\section{Proof of Proposition 4}

First note that Proposition 1 gives a sufficient condition for equilibria to exist that feature both parties basing their platforms on expert opinion in the extended model with polls. As we have argued in the main text, we only need to check for deviations of one party using a poll in order to find the conditions under which these equilibria survive. This gives the conditions for equilibrium existence in Item (1) and Item (2) 
of the proposition.

Consider the case where both parties use polls to inform their platforms. This implies in equilibrium $x_{1}=x_{2}$. Suppose party 1 deviates and chooses $x_{1} \neq x_{2}$. What does the electorate believe? Out of equilibrium beliefs of voters will be based on the answer to the question what could motivate party 1 to deviate? A deviating party faces three possible responses of the electorate:

1. The decisive voter always vote for party 2 .

2. The decisive voter always vote for party 1 .

3. The decisive voter votes in line with her signal.

Voters know that party 1 knows these three options. The probabilities of these options are independent of what party 1 actually chooses as the expert signals are not observable to the electorate. Then, given a deviation, it is optimal for party 1 to base $x_{1}$ on $w_{E}\left(w_{C}\right)$ iff $\sigma p_{E}+(1-\sigma)\left(1-p_{C}\right)>\frac{1}{2}\left(<\frac{1}{2}\right)$. Why? Consider $\sigma p_{E}+(1-\sigma)\left(1-p_{C}\right)>\frac{1}{2}$. Basing $x_{1}$ on $w_{E}$ dominates basing $x_{1}$ on $w_{C}$. It yields the same outcomes in case of (1) and (2), but leads to victory in case of informative voting. Given that basing $x_{1}$ on $w_{E}$ is the dominant deviation, it is also the most likely one. Hence, voters believe that in case of a deviation of party $1, x_{1}$ is based on $w_{E}$ if $\sigma p_{E}+(1-\sigma)\left(1-p_{C}\right)>\frac{1}{2}$ and on $w_{C}$ if $\sigma p_{E}+(1-\sigma)\left(1-p_{C}\right)<\frac{1}{2}$. This immediately implies the result in Item (1) as a deviation will become profitable whenever $q>\theta$ where all group $C$ voters switch to the deviant. To get the result in Item (2) note the group $C$ voters vote with a united front for the non-deviant party, unless the polling technology gets sufficiently ineffective relative to expert opinion such that they infer more about their state through the expert opintion on the other group than the poll result. This happens when $\theta<\alpha q+(1-\alpha)(1-q)$. 